\title{
EDUCAÇÃO DO CAMPO, ESCOLAS, RURALIDADES E O PROJETO DO PNE
}

\author{
Maria Antônia de Souza * \\ Patrícia Correia de Paula Marcoccia **
}

\begin{abstract}
RESUMO
Este artigo problematiza educação do campo, os aspectos da realidade das escolas públicas e as metas previstas no projeto do Plano Nacional de Educação (2011-2020). O trabalho, fruto de análise documental e bibliográfica, toma por referência a educação do campo como derivada da experiência coletiva dos movimentos sociais de trabalhadores. Em meio ao debate da educação nacional é necessário reconhecer que o Brasil possui identidades e ruralidades que são determinadas por projetos políticos diferenciados. A tensão entre latifúndio e terra como meio de vida e de trabalho é permanente na história brasileira. A partir do final da década de 1990, simpósios, seminários e conferências demonstraram o caráter público e coletivo da educação do campo, em oposição ao caráter tecnicista e urbano que historicamente marcou a educação rural no Brasil. Constata-se que a conjuntura política nacional foi favorável à efetivação das demandas feitas pelos trabalhadores do campo, embora com muitos limites e controles fiscais e jurídicos. O Projeto do Plano Nacional de Educação insere a educação do campo como uma ampla frente de necessidades a serem enfrentadas e realidades a serem reconhecidas.
\end{abstract}

Palavras-chave: Educação do campo. Escola pública. Ruralidades. Política educacional.

\begin{abstract}
RURAL EDUCATION, PUBLIC SCHOOLS, RURALITIES AND THE PNE PROJECT

This article questions the rural education, aspects from reality of the public schools and the aims provided in the National Education Project of the Plan (2011-2020). The work is resultant of bibliographical and documental analysis. It takes as reference the rural education as derived from the collective experiences of the worker social movements. Amid National Education debate it's necessary recognize that Brazil has identities and ruralities, that are determined for differentiated political projects. The
\end{abstract}

\footnotetext{
* Geógrafa (UNESP/Presidente Prudente). Mestre e Doutora em Educação (UNICAMP). Docente do Programa de Pós-Graduação - Mestrado e Doutorado em Educação - da Universidade Tuiuti do Paraná (UTP). Bolsista Produtividade em Pesquisa do CNPq - 1D. Endereço para contato: Universidade Tuiuti do Paraná. Rua Sidnei Antonio Rangel, 238 - Santo Inácio. Curitiba (PR). CEP. 82010-330.maria.antonia@pq.cnpq.br; masouza@uol.com.br.

** Mestre em Educação pela Universidade Tuiuti do Paraná(UTP). Graduada em Pedagogia pela Universidade Federal do Paraná (UFPR). Pedagoga da Secretaria Municipal de Educação de Curitiba. Pesquisadora do Núcleo de Pesquisa em Educação do Campo, Movimentos Sociais e Práticas Pedagógicas (NUPECAMP).pa_tyleo@hotmail.com.
} 
tension between large state and land as a way of life and work is permanent in the brasilian history. Since the end of the 1990 decade symposia, meetings, conferences demonstrated the collective and public character of the rural education, in opposition to the urban and technicality character that historically marked the rural education in Brazil. It has been found out that the national political conjuncture it was favorable for the rural workers effective demands, although there were many limits and judicial and fiscal controls. The National Education Project of the Plan inserts the rural education as a wide front of necessities to be faced and realities to be recognized.

Keywords: Rural education. Public schools. Ruralities. Education policy.

\section{Introdução}

Na história da educação brasileira, a trajetória da educação do campo é recente e fruto das lutas dos movimentos sociais de trabalhadores. A sua gênese foi marcada por lutas pela viabilização de processos educativos planejados no coletivo de trabalhadores do campo, no contexto da luta pela terra; por diagnósticos da realidade educacional do país; por iniciativas do tipo parcerias na oferta da educação de jovens e adultos; e por demandas direcionadas aos governos (federal, estadual e municipal) no que tange à efetivação do direito fundamental e social que é a educação. E o mais importante é que a sua origem integra o cenário das lutas por um projeto popular para o Brasil e por um projeto de campo em que terra, trabalho e cultura são indissociáveis.

A educação do campo tem como marca a prática coletiva. Há outras frentes de trabalho educacionais "direcionadas" aos trabalhadores do campo, que entretanto carecem da valorização da cultura e do reconhecimento da sua capacidade de organização política. É o caso do Serviço Nacional de Aprendizagem Rural (SENAR), criado pela Lei no 8.315, de 23 de dezembro de 1991 (BRASIL, 1991), que, embora considere a cidadania como chave de todas as ações e projetos, tem uma atuação voltada para os trabalhadores e não uma ação oriunda da prática e necessidade sociopolítica deles.

Aproximadamente vinte anos se passaram desde as primeiras iniciativas de parceria entre a sociedade civil organizada (entidades do campo) e os governos. Todas permeadas de muitas tensões políticas. A luta pela terra foi marcada por enfrentamentos policiais, militares e inúmeros assassinatos. Desse contexto de enfrentamentos, tensões, controles ideológicos, judiciais e policiais emerge a educação do campo, identificada como tal a partir de 1998 .

Este texto traz o conjunto de relações que vem marcando a educação brasileira, particularmente no campo, para então compreender o que está disposto no Projeto de Lei $\mathrm{n}^{\circ} 8.035$, de 20 de dezembro de 2010, referente ao Plano Nacional de Educação para o decênio 2011-2020 (BRASIL, 2010b). Problematiza aspectos da escola pública localizada no campo no contexto das ruralidades brasileiras. $\mathrm{E}$ as suas reflexões são oriundas dos estudos realizados no Núcleo de Pesquisa em Educação do Campo, Movimentos Sociais e Práticas Pedagógicas (NUPECAMP), vinculado ao Programa de PósGraduação - Mestrado e Doutorado em Educação - da Universidade Tuiuti do Paraná (UTP).

A metodologia empregada na obtenção dos dados apresentados neste artigo é composta por um conjunto de técnicas de coleta de dados, a exemplo da análise de documentos publicados pelo governo federal e pelo Governo do Estado do Paraná; da realização de entrevista com professores das escolas localizadas no campo, especificamente para obtenção de dados quanto à realidade das escolas, lugar em que os impactos decorrentes das políticas públicas ainda são bem incipientes; e da realização de observação da Articulação Paranaense da Educação do Campo e do Comitê Estadual de Educação do Campo.

Destaca-se que o ponto de partida teórico é o reconhecimento da existência de duas ideologias marcando a educação (escolar e não escolar) da população do campo, atualmente. Trata-se da ideologia da educação rural, cuja identidade vincula- 
se à política de valorização do agronegócio. E a ideologia da educação do campo, cuja identidade está na prática coletiva de construção de conhecimentos emancipatórios e no cenário de um projeto nacional transformador das relações de exclusão, exploração e de desigualdades.

No que tange ao campo, entende-se que ele é marcado pela identidade fundada no trabalho e vida na terra ou nas águas. Entretanto, em oposição aos trabalhadores que vivem da terra, existem os latifúndios, que historicamente têm gerado expropriação e exclusão no campo. No Estado do Paraná, o agronegócio está explícito nas atividades da cana-de-açúcar e pinus, que têm contribuído para a ampliação do desemprego no campo em nome do desenvolvimento econômico e tecnológico. Também a produção de soja, trigo, milho, entre outros produtos para exportação, tem lugar no estado, na economia e na política, haja vista que os grupos que dominam a política governamental, em sua maioria, são defensores do avanço do agronegócio e críticos dos movimentos de trabalhadores, particularmente dos sem-terra.

$\mathrm{O}$ entendimento de política pública está vinculado ao conceito de participação efetiva e de espaço público. Portanto, a política pública em construção no âmbito da educação do campo tem relação direta com a prática coletiva dos povos do campo. No estado do Paraná, essa realidade é evidente, principalmente na conjuntura política do período de 2003 a 2010. Os moradores das áreas remanescentes de quilombos e os moradores das ilhas do litoral paranaense, por exemplo, vivenciaram processos coletivos de definição dos projetos político-pedagógicos das escolas públicas estaduais, acontecimento inédito na história da educação paranaense; afinal, os povos da ilhas, os quilombolas e os faxinalenses nunca tiveram a sua realidade escolar problematizada no âmbito da política pública.

\section{Educação rural, educação do campo e escola pública}

Para falar da emergência da educação do campo é necessário uma retrospectiva da história da educação rural e das críticas inerentes a ela. Tomando como marco a década de 1980, conjuntura em que a migração campo-cidade, embora continuasse, já havia invertido a realidade populacional brasileira, muitas iniciativas políticas interferem na então denominada educação rural.

Escolas públicas rurais (estaduais e municipais) foram fechadas sob a alegação de que o número de alunos não era suficiente para a manutenção das turmas e classes escolares. Por sua vez, a década de 1980 foi marcada pelo processo de nucleação ou consolidação de escolas rurais. Ou seja, escolas isoladas e unidocentes foram desativadas e núcleos rurais foram selecionados para sediar a instituição escolar, que receberia alunos de diversos lugares do município.

Entrou em cena a polêmica do transporte escolar rural, que nos dias atuais merece estudos, especialmente no que tange ao financiamento da educação, às condições de transporte dos alunos e condições de trabalho dos professores. No Estado do Paraná, o ano de 2011 começou com diversos noticiários sobre o transporte escolar, como as condições precárias do transporte, as verbas e a interrupção do transporte em algumas localidades, tanto para alunos quanto para o deslocamento dos professores.

Como o foco deste artigo é a educação do campo no Projeto de Lei $n^{\circ} 8.035 / 2010$, cabe a primeira pergunta: Que políticas públicas de transporte escolar estão sendo garantidas para o deslocamento dos alunos e professores, prioritariamente intracampo? Esse Projeto de Lei apresenta políticas de financiamento para a aquisição de transporte escolar adaptado para atender aos alunos com deficiência? Trata-se de elementos que devem estar contemplados nas metas de financiamento da educação e nas condições de trabalho.

Retomando os anos de 1980, constata-se a existência do processo de nucleação - organização de uma unidade escolar numa comunidade rural que fosse central/nuclear em relação às demais. Outras regiões tiveram perda de escolas e ausência de transporte escolar. Os jovens foram os principais afetados, pois, para ter acesso ao ensino de $2^{\circ}$ grau (atual Ensino Médio), era necessário dirigir-se à escola da cidade. Com isso, processos de exclusão escolar marcaram a vida da população do campo na década de 1980.

Ainda hoje o número de escolas de Ensino Médio no campo é reduzido, como aponta pesquisa 
do Instituto Nacional de Estudos e Pesquisas Educacionais Anísio Teixeira (INEP, 2007).

Para melhor entender a questão, os interessados podem efetuar uma análise dos processos de migração campo-cidade nas diferentes localidades brasileiras, o que é essencial para entender alguns aspectos da educação rural. Também é fundamental analisar as conjunturas econômicas e políticas que levaram aos processos migratórios, processos de exclusão social, e neles a exclusão escolar. Cada conjuntura deve ser analisada diante dos condicionantes estruturais históricos, a exemplo da concentração da riqueza e da terra, que tamanha contradição social gera no país.

A Lei $n^{\circ}$ 9.394, de 20 de dezembro de 1996, artigos 26 e 28 , estabelece a organização curricular diferenciada para as escolas rurais. Conforme dispõe o artigo 28:

Na oferta da educação básica para a população rural, os sistemas de ensino promoverão as adaptações necessárias à sua adequação, às peculiaridades da vida rural e de cada região, especialmente. Incisos: I- Conteúdos curriculares e metodologias apropriadas às reais necessidades e interesses dos alunos da zona rural; II- Organização escolar própria, incluindo a adequação do calendário escolar as fases do ciclo agrícola e as condições climáticas; III- Adequação à natureza do trabalho na zona rural (BRASIL, 1996).

$\mathrm{O}$ artigo 26 estabelece que:

Os currículos do ensino fundamental e médio devem ter uma base nacional comum, a ser complementada, em cada sistema de ensino e estabelecimento escolar, por uma parte diversificada, exigida pelas características regionais e locais da sociedade, da cultura, da economia e da clientela (BRASIL, 1996, grifo nosso).

Tais artigos são sustentados pela disposição presente no texto constitucional, especificamente o artigo 210, que versa sobre os conteúdos mínimos para o ensino fundamental, com respeito aos valores culturais e de modo a assegurar uma formação básica comum.

Do ponto de vista da legislação, até o final da década de 1990 as disposições sobre a educação rural sempre foram tímidas na legislação constitucional e educacional. Foram os movimentos sociais de trabalhadores rurais que trouxeram para o ordenamento jurídico-educacional (diretrizes, resoluções, portarias, decretos) a concepção da educação do campo.

A década de 1990 foi marcada pela realização do I Censo Nacional da Reforma Agrária, por meio do qual foi constatado o elevado grau de analfabetismo e baixa escolaridade entre os beneficiários da reforma agrária (INCRA, 1996), ao lado dos percentuais também indicados pelo Instituto Brasileiro de Geografia e Estatística (IBGE) sobre a frágil escolaridade verificada entre os povos do campo. Esse fato gerou inquietações sobre as escolas localizadas nos assentamentos organizados no Movimento dos Trabalhadores Rurais Sem Terra (MST). Desde então houve intensa produção de materiais pedagógicos por parte dos integrantes do MST responsáveis pelo Setor de Educação, bem como encontros estaduais e nacionais. Em 1997 foi realizado o I Encontro Nacional de Educadores e Educadoras da Reforma Agrária, seguido da I Conferência Nacional por uma Educação Básica do Campo, em 1998. Desse período em diante constituiu-se um espaço público de debate, dos povos do campo, sobre a educação em sentido amplo, sobre as políticas educacionais e sobre um projeto de campo necessário àqueles que vivem e trabalham com a terra.

Foi assim que a concepção de educação do campo foi trilhada nos coletivos educacionais dos movimentos sociais, em relação com as instâncias governamentais, e expressando as diversas lutas no cenário público das conferências e seminários estaduais e nacionais.

A concepção de Educação do Campo foi cunhada pelos movimentos sociais de trabalhadores e sistematizada por autores como Bernardo Mançano Fernandes, Miguel Arroyo, Mônica Castagna Molina, Roseli Salete Caldart, entre outros. Até então, na história da educação brasileira falava-se de uma educação para os povos do campo. Contudo outra concepção de educação foi construída e praticada coletivamente entre os povos do campo.

Delineou-se, ao final da década de 1990, o conceito de política pública como construção coletiva, como fruto do debate no espaço público. A prática coletiva gerou sinais de mudança no próprio Estado e em alguns governos, embora sinais tímidos e determinados pelas contradições do modo de produção capitalista. 
Em 1998, foi criado o Programa Nacional de Educação na Reforma Agrária (PRONERA), como fruto dos encontros de 1997 e 1998. Foi esse programa que possibilitou o desenvolvimento de projetos de educação de jovens e adultos; cursos de especialização lato sensu aos professores das escolas do campo; abertura de cursos de Pedagogia (conhecido como Pedagogia da Terra) destinados aos profissionais que trabalhariam nas escolas localizadas nos assentamentos da reforma agrária. O referido programa é, portanto, fruto da luta dos trabalhadores organizados do campo. E tem sido alvo de questionamentos por parte de procuradores do Ministério Público Federal, bem como do Tribunal de Contas da União. Ou seja, há uma evidente tensão no controle fiscal e judiciário quanto à realização de cursos universitários aos beneficiários da reforma agrária.

Os encontros nacionais da educação do campo e a criação do PRONERA possibilitaram inúmeras experiências, articulando o princípio da indissociabilidade ensino-extensão-pesquisa nas universidades brasileiras, vinculadas aos interesses e necessidades dos trabalhadores do campo.

No final da década de 1990, iniciou-se a preparação para a elaboração das Diretrizes Operacionais para a Educação Básica nas escolas do campo, documento aprovado em 3 de abril de 2002 (BRASIL, 2002).

Foi, portanto, uma década de conquistas para a educação do campo, fruto do empenho dos povos organizados do campo, enfim, da ação dos trabalhadores do campo e trabalhadores da educação nesse país. Entretanto, essas conquistas ocorreram em meio a inúmeros conflitos e represálias ideológicas e jurídicas.

No documento nacional Diretrizes Operacionais para a Educação Básica das escolas do campo estão presentes artigos que fortalecem a necessidade de projetos político-pedagógicos diferenciados às escolas do campo. As Diretrizes dispõem sobre organização curricular, horários, articulação com a comunidade e, especialmente, encaminhamentos para a definição da identidade dos povos do campo, algo pouco discutido até então, tanto na legislação quanto nas instâncias governamentais e na academia.

No ano de 2004 foi criada a Secretaria de Educação Continuada, Alfabetização e Diversidade (SE-
CAD), que tem respondido por diversos programas de educação do campo na atualidade. Em 2008, houve aprovação das diretrizes complementares às diretrizes operacionais da educação do campo (BRASIL, 2008). No documento está explícita a preocupação com a educação especial, educação infantil e com a localização das escolas no próprio campo, de modo a evitar longos deslocamentos em transporte - pelas crianças e jovens.

Em 4 de novembro de 2010, foi aprovado o Decreto do Presidente da República dispondo sobre a política de educação do campo e sobre o PRONERA. Trata-se de um documento estratégico de valorização da educação do campo no Estado e nas esferas governamentais, especialmente num momento de transição política (BRASIL, 2010a). Cabe destacar que vários estados brasileiros têm a sua organização em torno da educação do campo construída a partir do final da década de 1990 e, especialmente, na primeira década do século XXI.

O Estado do Paraná, por exemplo, viveu o auge do debate da educação do campo nos últimos oito anos. Houve parecer do Conselho Estadual de Educação sobre a educação do campo, seguido de publicação de resolução da Secretaria de Estado da Educação sobre a política estadual da educação do campo. O estado possui um Comitê Estadual de Educação do Campo e um Grupo de Trabalho formado pelas Instituições de Educação Superior do Estado. Entretanto, no início do novo governo estadual, em 2011, as intempéries e incertezas começam a emergir. Pergunta-se: a prática política de diálogo com os movimentos sociais terá continuidade ou não? As atividades em parceria, movimentos sociais e governo terão continuidade ou não? $\mathrm{O}$ momento é de dúvida, atenção e articulação dos movimentos de trabalhadores, universidades e entidades sociais vinculadas à educação do campo.

No Brasil, o período de 1998 a 2010 foi marcado pela criação de inúmeros cursos de Educação Superior demandados pelos beneficiários da reforma agrária. Eles se desenvolvem no contexto das contradições internas do Estado, muitas vezes expressas no campo jurídico, a exemplo das ações civis públicas que o Ministério Público Federal impetrou em vários estados. É o caso das ações e processos em andamento no Estado do Rio Grande do Sul, pelo fechamento do curso de Medicina Veterinária 
da Universidade Federal de Pelotas e, no Estado de Goiás, pelo fechamento do curso de Direito ofertado pela Universidade Federal de Goiás.

Em síntese, o panorama dos últimos anos no que diz respeito à educação do campo é de experiências coletivas em várias frentes. E é certo que os movimentos sociais de trabalhadores têm interrogado muitas práticas educativas (escolares e não escolares) da história passada, do presente e do futuro.

A identidade das escolas do campo tem sido problematizada pelo menos nos últimos dez anos e os estados têm publicado documentos sobre o assunto. Emerge o debate sobre a identidade e as ruralidades do país. Povos Quilombolas, Faxinalenses (no Paraná), acampados, assentados, boias-frias, ilhéus, ribeirinhos, entre outros, têm lugar central no debate da política educacional do campo e nos projetos de campo e de país que se deseja construir. O debate é sempre tenso, pois ele indaga o avanço do agronegócio e os processos de exclusão dele decorrentes.

A formação inicial e continuada de professores tem sido intensificada nos últimos anos por meio de parcerias entre governos, universidades, movimentos sociais, entidades sociais, etc. A Pedagogia da Alternância é uma concepção educacional que tem orientado muitas práticas formativas, entretanto existem diversas frentes do que se denomina Alternância, e elas podem atender a ideologias diferenciadas.

Materiais bibliográficos e pedagógicos têm ampla produção na academia, nos movimentos sociais e nas instâncias governamentais, embora com potencial e necessidade para crescimento. Teses e dissertações vêm sendo produzidas sobre a educação do campo e sobre a história da educação rural, tanto no Brasil quanto em outros países da América Latina. Os eventos acadêmico-científicos têm criado eixos para debate da educação do campo e têm recebido trabalhos que investigam diferentes temas relacionados à educação e às ruralidades $\mathrm{e}$ territorialidades brasileiras.

É preciso avançar na direção de mudanças na realidade da escola do campo. A escola ainda está marcada por uma ideologia que valoriza os conhecimentos universais em sua relação com a vida na cidade e não em relação com a vida e o trabalho na terra. Aí parece residir um desafio fundamental. Para que haja transformação no mundo da escola é importante que os cursos de formação de professores - tanto inicial quanto continuada - deem atenção à realidade dos povos do campo no país. Nem mesmo estágios em escolas do campo são valorizados nas universidades. É preciso avançar no conhecimento acerca da realidade brasileira que, certamente, não é exclusivamente urbana.

Outro desafio está na esfera econômica e na definição de projeto político para o país. No campo, a força do agronegócio tem oprimido e expulsado trabalhadores. A ampliação da produção da canade-açúcar em inúmeros municípios tem sido sinônimo de exclusão do trabalhador rural. É importante refletir sobre quais questionamentos a instituição escolar faz sobre as contradições sociais e as desigualdades que marcam e demarcam a sociedade.

A articulação entre os municípios, os estados e a União constitui outro desafio. Cabe perguntar como está a atuação do governante no que tange à valorização das iniciativas de fortalecimento do trabalho na agricultura e das políticas sociais, especialmente para a saúde e educação, tão frágeis no meio rural brasileiro. Os municípios têm potencial para ampliar os processos formativos dos professores que trabalham nas escolas do campo. Conhecer as diferentes experiências em desenvolvimento no país é um dos meios para a transformação no espaço local. O país conta com praticamente $50 \%$ das escolas do campo com classes e/ou turmas multisseriadas. É preciso avançar no estudo dessa realidade e nos potenciais que ela oferece para a formação das crianças e jovens do campo.

Ainda existe o desafio quanto ao vínculo de trabalho do professor. Em muitos estados o professor não é concursado e possui trabalho temporário nas escolas do campo. É preciso superar essa realidade, senão haverá a institucionalização do que denominamos "permanente chegada do novo nas escolas", ou seja, a rotatividade de professores. É uma realidade que fragiliza o desenvolvimento de um projeto político-pedagógico coletivo, crítico e democrático, além, obviamente, de revelar a fragilidade no que tange às relações de trabalho.

Diante de todos esses desafios, indaga-se sobre o conteúdo que está posto no Projeto de Lei - Plano Nacional de Educação - para o próximo decênio. 
Antes de discutir algumas das metas propostas no projeto, considera-se fundamental a reflexão sobre aspectos da ruralidade brasileira.

\section{Educação, escolas e ruralidades}

Em pesquisa sobre os movimentos sociais e a educação do campo, Souza (2010) indica seis aspectos a serem levados em conta quando se busca compreender as relações produzidas no campo no Brasil, a saber:

1. Os territórios das lutas sociais que expressam o confronto entre classes sociais e dão visibilidade à concentração da terra e à geração de processos de expropriação e expulsão dos trabalhadores da terra. Os territórios das relações sociais que produzem vida, trabalho e cultura. Os sujeitos das territorialidades, trabalhadores que resistem criativamente às contradições e intempéries (climáticas e políticas) que marcam o campo brasileiro.

2. Os trabalhadores com graus diferenciados de organização política: trabalhadores (lavradores) voltados à agricultura familiar e não organizados em movimentos sociais; trabalhadores articulados politicamente no MST e inúmeros movimentos sociais; trabalhadores empregados nas fazendas de gado, áreas canavieiras, entre outras atividades produtivas; ribeirinhos, ilhéus, faxinalenses, sitiantes, povos das florestas, entre outros. Esses estão em franca oposição aos grandes proprietários ou latifundiários de terra, que, em sua maioria, não moram no campo, e cuja produção está voltada à exportação ou utilização da terra como meio de acumulação de riquezas.

3. A existência de política agrícola que integra linhas de crédito voltadas à produção para exportação; linhas de créditos para áreas de reforma agrária; linhas de crédito para a agricultura familiar. $\mathrm{O}$ acesso ao crédito agrícola tem duas faces: de um lado, a organização política do grupo social para adquirir os créditos; de outro, a supervalorização de créditos destinados à produção para exportação. A disponibilização de créditos acompanha a histórica desigualdade de oportunidades que marca o campo brasileiro. Atrela-se a isso o fator informação. Os grandes proprietários têm acesso a todo tipo de assessoria técnica e jurídica para lidar com os financiamentos agrícolas e negociações de sua produção. É um desafio para os trabalhadores da agricultura familiar - organizados ou não em movimentos sociais - ter acesso e possibilidade de negociação dos créditos agrícolas. O trabalhador isolado, muitas vezes, não tem o conhecimento técnico necessário para adquirir e planejar, de modo adequado, a utilização do recurso financeiro. Os trabalhadores reunidos em movimentos sociais têm maior possibilidade de atingir tais conhecimentos técnicos, como o estudo dos contratos, articulação para negociar prazos para pagamento do financiamento, etc.

4. As lutas pela sobrevivência no seio da sociedade capitalista, competitiva. Os trabalhadores buscam estratégias de diversificação da produção agrícola como meio de manter a sobrevivência da família no campo. A organização de cooperativas e núcleos de base é intensificada como meio para potencializar a participação dos trabalhadores e a gestão coletiva da produção.

5. A migração dos jovens em direção às cidades ainda é realidade. Os trabalhadores organizados resistem, criando alternativas para o trabalho do jovem no campo, como a diversificação da produção agrícola e a produção agroecológica. Pessoas aposentadas têm forte presença no campo e estão inseridas nas atividades produtivas.

6. O processo de aglomeração de pequenas propriedades nos municípios de menor população. Propriedades que antes foram repartidas e comercializadas na forma de pequenos sítios hoje parecem estar em processo de concentração, novamente. São propriedades adquiridas por pessoas que não têm o interesse de moradia e de trabalho nelas, e muitas vezes constituem áreas para pastagens e arrendamento para determinados cultivos, como a plantação de cana-de-açúcar. 
Dessa forma, o campo é compreendido no conjunto das relações sociais desiguais que caracterizam o modo de produção capitalista e, especialmente, como lugar de vida e de trabalho. É lugar de violentos confrontos sociais que marcam a história do Brasil. No campo existem dois modelos de desenvolvimento econômico: de um lado, um modelo que está atrelado à produção para exportação e que exclui os trabalhadores; de outro lado, um modelo vinculado à agricultura familiar e sustentável.

O campo brasileiro, com uma população de aproximadamente $18 \%$ dos que habitam o território nacional, é significativo para a economia interna e externa; é lugar de vida, de moradia e de trabalho de milhares de pessoas. Além disso, os municípios cujos núcleos urbanos são minúsculos possuem relações econômicas e sociais rurais. Basta observamos o interior do Brasil: excluindo as capitais e as poucas cidades de porte médio, a maioria constitui-se de municípios com pequenos núcleos urbanos e área rural ocupada por grandes e pequenas propriedades. A população que vive na periferia urbana, muitas vezes, trabalha na área agrícola, quando ela não está totalmente mecanizada. A maioria da população urbana é oriunda da área rural, tendo partido para as cidades em razão da diminuição do trabalho no campo e da busca de melhores condições de vida - um processo doloroso de expropriação e expulsão dos trabalhadores do seu lugar de vida e de produção da existência.

Embora tenhamos registro de movimentos sociais do campo em toda a história brasileira, é possível afirmar que o século XX teve uma diversificação e predominância de movimentos. É o caso das Ligas Camponesas, lutas de boias-frias, lutas sindicais, lutas de posseiros, movimentos de trabalhadores rurais que culminaram na gênese do MST no final dos anos de 1970, enfim, uma diversidade de lutas pela terra a partir do final dos anos de 1990 e a atuação da Via Campesina na primeira década do século XXI. O MST consolidou-se como força opositora ao Estado. Inseriu na agenda política temas como viabilidade socioeconômica dos assentamentos de reforma agrária, educação e desenvolvimento sustentável. O Estado do Paraná conta com a Escola Latino-Americana de Agroecologia, cujo projeto político-pedagógico fundamenta-se na sustentabilidade socioambien- tal e na organização política dos trabalhadores. Estudantes de países como Argentina, Paraguai, Venezuela, entre outros, têm sido alunos na escola localizada no município da Lapa, Estado do Paraná. Os Institutos Federais, com ensino técnico, têm tido forte atuação no estado, especialmente com cursos voltados à agroecologia.

Especificamente sobre o campo e a educação escolar no Estado do Paraná, Pereira (2002) apresenta dados da segunda metade do século XX. Ele mostra que em 1950 a população do campo no estado era $78 \%$, ao passo que em 1985 passa a ser de $35 \%$. Nos anos de 1940 , de cada 100 habitantes do estado, 76 moravam na área rural. O total de matrículas na área rural era de 560.439 no ano de 1976 e de 362.967 no ano de 1986. Das 13.885 escolas primárias existentes no ano de 1976 , 11.578 estavam localizadas no campo, e a grande maioria das escolas (80\%) era municipal. Grande parte delas era isolada e foi afetada pelo processo de migração dos anos de 1970.

As autoridades municipais começaram a discutir alternativas para as escolas que então ficavam com número reduzido de alunos. Uma delas foi a "centralização" ou "nucleação" das escolas, colocando em funcionando o transporte municipal de alunos. $\mathrm{O}$ autor salienta que " $[. .$.$] os idealizadores do Movimento$ Paranaense das Escolas Consolidadas se inspiraram no conceito do Movimento Americano das Escolas Consolidadas". (PEREIRA, 2002, p. 51).

O mesmo autor destaca que:

O movimento das escolas consolidadas propunha nada mais do que a criação de escolas para crianças da região rural que fossem tão boas quanto as que crianças da cidade já estavam freqüentando. Em geral, as vantagens eram as de uma escola grande com o apoio financeiro adequado e um bom número de alunos. (PEREIRA, 2002, p. 60).

O contexto da existência das escolas consolidadas norte-americanas e o contexto brasileiro eram semelhantes quanto ao aspecto socioeconômico, particularmente de forte migração campo-cidade e industrialização, porém diferentes no contexto político-educacional.

Atualmente, a população do Paraná é de 10.284.503, segundo o IBGE (2007). O número de escolas localizadas no campo é de 1.332 pertencentes à rede municipal e 423 estaduais registradas ofi- 
cialmente. Entretanto, a Coordenação da Educação do Campo ${ }^{1}$, da Secretaria de Educação do Estado, afirma que são 583 escolas da rede estadual. Há uma polêmica no momento do registro das escolas (rurais ou urbanas) no sistema estadual. Existem localidades como os distritos que são eminentemente rurais, entretanto as escolas são registradas como urbanas. Esse fato gera diferença entre o registro oficial e o registro identificado por meio de levantamento de dados com as comunidades e diretores das escolas estaduais.

A Coordenação da Educação do Campo registra que no ano de 2000 existiam 2.725 escolas municipais no estado, o que evidencia a política do fechamento das escolas. Outra realidade no estado é quanto aos professores e sua relação de trabalho: $50,60 \%$ deles trabalham pelo regime de Processo Seletivo Simplificado (PSS). Eles podem ficar até 2 anos na escola, pois não são professores do Quadro Permanente do Magistério (QPM). Esse fator contribui para a frequente passagem do professor pelas escolas do campo, conhecida como "rotatividade de professores".

A taxa de urbanização no estado, segundo dados do IBGE (2000), é de 81,4\%. É importante analisar os dados sistematizados pelo Instituto Paranaense de Desenvolvimento Econômico e Social acerca da distribuição da população nos 399 municípios do estado. Como pesquisadora do referido Instituto, Valéria Verde (2004) analisa a distribuição da população pelo território paranaense. Ela mostra que o estado tem sete aglomerações urbanas que envolvem 47 municípios; que há predomínio de municípios com baixa densidade demográfica; que dos 352 municipios (já excetuando as aglomerações urbanas, 47 municípios citados), 302 possuem população com até 20 mil habitantes, de acordo com os dados do IBGE (2000). Ainda, menciona que dos 399 municípios que integram o estado, 345 têm densidade demográfica inferior a 80 habitantes por $\mathrm{km} 2$. A autora mostra que $53 \%$ da população economicamente ativa está vinculada a atividades de agropecuária ou suas derivadas. $\mathrm{O}$ que tais números revelam? Como afirma Veiga (2003, p. 65), "o Brasil é menos urbano do que se calcula". Ele afirma que os parâmetros da Organização de

\footnotetext{
${ }^{1}$ Dados informados pela Equipe da Coordenação da Educação do
} Campo em julho de 2010.
Cooperação e de Desenvolvimento Econômico para classificar uma localidade como urbana é de que tenha 150 hab./km2. Para ele, "por esse critério, apenas 411 municípios dos 5.507 municípios brasileiros existentes em 2000 seriam considerados urbanos."

Essa contextualização nos permite afirmar que grande parcela da população brasileira vivencia relações sociais, culturais e econômicas assentadas no trabalho agrícola, na pesca, nas florestas, nos rios. Terra e água são dois lugares trabalhados e vividos por povos ribeirinhos, ilhéus, assentados, acampados, boias-frias, quilombolas, indígenas, pequenos agricultores/ sitiantes/ colonos/ sertanejos, entre tantos outros. A sua identidade sociocultural é marcada pelas relações de trabalho na terra e na água. E as escolas, o que nos ensinam da vida dos povos do campo? Já não podemos responder tal indagação de modo negativo.

Após apontar aspectos da trajetória da educação do campo, da realidade das escolas e particularidades dos povos que vivem e trabalham na terra e nas águas brasileiras, cabe tecer análises sobre o conteúdo proposto no projeto do Plano Nacional de Educação, em discussão no Congresso Nacional no ano de 2011.

\section{Educação do campo no Projeto de Plano Nacional de Educação}

O Projeto de Lei ${ }^{\circ} 8.035$, de 20 de dezembro de 2010, referente ao Plano Nacional de Educação (PNE) para o decênio 2011-2020 (BRASIL, 2010b), ora levado ao Congresso Nacional para apreciação, não representa o resultado sistematizado do documento final da Conferência Nacional da Educação (CONAE, 2010). Por meio de conferências municipais, intermunicipais, estaduais e nacionais, a CONAE teve, ou tem, a tarefa de construir orientações na política educacional que ultrapassem as políticas em vigor, com a responsabilidade de incorporar o que os movimentos sociais vêm reivindicando à comunidade científica e outros segmentos da sociedade e do governo.

O novo PNE contemplou alguns princípios e diretrizes da proposta final da CONAE, porém é importante destacar que o documento da CONAE trazia nas suas pautas discussões, necessidades e 
consensos, mas também refletia tensões no campo da educação e da educação do campo, tais como a reunião, num mesmo eixo identificado como Justiça Social, Educação e Trabalho: Inclusão, Diversidade e Igualdade", de nove temáticas, dentre as quais a educação do campo (CONAE, 2010). Cada uma das temáticas trazia diferentes especificidades históricas, políticas e lutas sociais. O governo, ao agregar no mesmo eixo nove temáticas, reconhece as dificuldades no trato das diferentes perspectivas, com histórias muito diferentes, inclusive de organização dos movimentos sociais.

Nesse sentido, compreende-se que o debate da educação do campo e de outros segmentos ficou prejudicado, pois resta a interrogação: como efetivar políticas e garantir as necessidades desses segmentos se não foram garantidos debates quanto às particularidades dos diferentes grupos? Embora seja necessário reconhecer que o Projeto de Lei n ${ }^{\circ} 8.035$ do Plano Nacional de Educação estabelece diretrizes para a educação do campo, (re)afirma o discurso governamental de reconhecimento da diversidade dos sujeitos na garantia do direito à Educação.

A concepção e a proposta da educação do campo vão além do que os discursos governamentais estabelecem. A educação do campo tem como meta principal a luta dos trabalhadores do campo para a construção de um modelo de educação que considere a sua realidade e interesses, valorizando os diferentes "grupos identitários" e a sua produção da existência. Dentre esses grupos, consideram-se os ribeirinhos, os indígenas, os quilombolas, os assentados da reforma agrária, os agricultores e os assalariados rurais - todos formam a categoria "sujeito histórico". "O que os particulariza é a prática social, cultural. O que os une são as relações de trabalho com a terra e a pertença à classe trabalhadora, em oposição à classe latifundiária" (SOUZA, 2010, p. 54).

Considerando a diversidade cultural, econômica e social desses grupos, pode-se afirmar que há um objetivo em comum: a luta pelo direito a uma educação universal e de qualidade. E essa "universalidade considera o direito a especificidades e singularidades como algo universal e geral. Assim, na mesma medida, ao cultivarem identidades próprias, os povos do campo são sujeitos de direito ao trato diferenciado" (MUNARIM et al., 2009, p. 58).
Nessa mesma linha de pensamento, Frigotto (2010, p. 36) afirma que a educação e a pedagogia do campo devem partir da particularidade e singularidade dadas pelos sujeitos que produzem suas vidas no campo. "Todavia, não se postula o localismo e nem o particularismo, mediante os quais se nega o acesso e a construção do conhecimento e de uma universalidade histórica."

O Projeto de Lei $n^{\circ} 8.035$ estabelece em seu artigo $8^{\circ}$, parágrafo $\S 1^{\circ}$, que: “Os entes federados deverão estabelecer em seus respectivos planos de educação metas que considerem as necessidades específicas das populações do campo e de áreas remanescentes de quilombos, garantindo equidade educacional" (BRASIL, 2010b). Importante indagar quais metas devam ser consideradas.

O pensamento de Caldart (2003) sinaliza um caminho para pensar o que é escola do campo. A escola do campo para a autora não é uma escola diferente, mas uma escola que reconhece seus sujeitos sociais e os incorpora para dentro da escola, valorizando seus saberes, suas crenças, seu trabalho e sua cultura. Admitindo que esses sujeitos possam intervir e modificar as relações sociais de seu grupo.

A questão é: para construir essa escola que a autora propõe é necessário que os sujeitos que dela necessitam lutem e se mobilizem para fazer com que a escola se volte para os sujeitos sociais reais. Nessa perspectiva, a educação do campo está adiantada diante de muitas concepções de educação, pois tem "clareza de que sozinha a escola não provocará isto. Ao contrário, é o movimento social que precisa ocupar e ocupar-se da escola, construindo junto com os educadores que ali estão o seu novo projeto educativo" (CALDART, 2003, p. 72).

Logo, a educação do campo "vincula a luta por educação com o conjunto das lutas pela transformação das condições de vida do campo" (CALDART, 2004, p. 152), articulando com a ciência, a cultura, a experiência e o trabalho.

Essa situação impõe alguns desafios entre o que o Projeto de Lei $n^{\circ} 8.035 / 2010$ discute enquanto política de atendimento às populações do campo e a proposta da educação do campo que articula a educação a "mudanças radicais no projeto societário", como afirma Frigotto (2010).

O contexto em que está inserido o projeto de lei do PNE revela uma forte impregnação das políti- 
cas de âmbito federal, a fim de não ultrapassar o proposto atualmente, nos termos do que se tem em política nacional. Embora o projeto de lei do PNE tenha como bandeira os princípios já mencionados, eles não estão comprometidos com um projeto de educação que prepare os trabalhadores para ser uma "classe detentora do capital, apta a concorrer com o capitalismo central", pois como afirma Frigotto (2010, p. 29):

[...] o projeto de capitalismo dependente impediu e impede, por diferentes mecanismos, a universalização da educação escolar básica (fundamental e média), pública, laica e unitária, mesmo nos limites dos interesses de um capitalismo avançado, dentro de um projeto de autonomia nacional.

Não obstante isso, o Projeto de lei do PNE contempla nas suas diretrizes alguns elementos para garantir condições e meios à população do campo para frequentar as escolas públicas do campo, bem como um projeto pedagógico e uma prática pedagógica que se articulam a algumas discussões da educação do campo.

A interface entre a educação especial e educação do campo é uma temática que está inserida no projeto de lei do PNE, na estratégia 4.2, que estabelece a implantação de salas de recursos multifuncionais e a formação continuada de professores para o atendimento educacional especializado complementar, nas escolas urbanas e rurais (BRASIL, 2010b). No entanto, este debate é incipiente diante das demandas da educação especial no campo.

A pesquisa de Marcoccia (2011), realizada no Estado do Paraná, revela que as condições dos alunos com deficiência, transtornos globais de desenvolvimento e altas habilidades/superdotação nas escolas públicas do campo são marcadas pela precariedade de recursos físicos, materiais e pedagógicos. Além disso, a autora destaca outros fatores da concretude do dia a dia que interferem no acesso e na permanência desses alunos nas escolas públicas do campo, entre eles: lugares de difícil acesso, estradas precárias e a utilização do transporte escolar por longas distâncias e sem adaptação.

A educação infantil também está inserida no texto do Projeto de Lei do PNE, conforme dispõe a estratégia 1.7:
Fomentar o atendimento das crianças do campo na educação infantil por meio do redimensionamento da distribuição territorial da oferta, limitando a nucleação de escolas e o deslocamento das crianças, de forma a atender às especificidades das comunidades rurais (BRASIL 2010b).

A ampliação da educação infantil nas comunidades rurais contribui para a visibilidade social e política das crianças do campo, porém é preciso garantir a transversalidade da educação do campo na educação infantil nas propostas das secretarias municipais, priorizando discussões que envolvam a formação de professores de educação infantil do campo, projeto pedagógico e práticas pedagógicas.

A formação de professores do campo está prevista no Projeto de Lei do PNE que estabelece a implementação de "programas específicos para a formação de professores para as populações do campo, comunidades quilombolas e povos indígenas" (BRASIL, 2010b). É preciso garantir formação continuada e formação inicial, pois a rotatividade e o pouco tempo lecionando nas escolas do campo dificultam o fortalecimento da identidade das escolas do campo. Daí a importância do Estado garantir políticas públicas para a universalização da educação superior à população do campo, especialmente nas licenciaturas. Além disso, é necessário discutir as condições de trabalho dos professores que atuam nas escolas do campo, transporte escolar e estabilidade profissional para que permaneçam nas escolas do campo.

O Projeto de Lei 8.035 dispõe, sobre o transporte escolar, que a frota rural deve ser ampliada, renovada e padronizada, bem como garantido o transporte intracampo, "cabendo aos sistemas estaduais e municipais reduzir o tempo máximo dos estudantes em deslocamento" (BRASIL, 2010b).

A ampliação do percentual mínimo de vinculação de cada esfera administrativa e um aumento da porcentagem do PIB a ser aplicado na educação tende a refletir na melhoria da qualidade do ensino e, portanto, na melhoria da educação escolar da população do campo. A meta 20 do Projeto de Lei $n^{\circ}$ 8.035, de 2010, dispõe: "Ampliar progressivamente o investimento público em educação até atingir, no mínimo, o patamar de sete por cento do produto interno bruto do país" (BRASIL, 2010b). 
Monlevade (2010, p. 8) afirma que essa meta é o "calcanhar de Aquiles" da educação brasileira; contudo, não basta estabelecer um percentual mínimo para todo o país, é preciso que o novo PNE formule "uma meta estruturante para distribuir entre a União, os Estados e os Municípios o percentual mínimo a ser gasto em educação".

Nesse sentido, a política de financiamento da educação do campo necessita de um repasse diferenciado, pois o custo aluno do campo demanda mais recursos do que a realidade urbana. Portanto, é necessário acompanhar e cobrar a execução da ampliação do financiamento da educação, especialmente da educação do campo. Caso contrário, o discurso do projeto de lei do PNE não chegará ao chão da escola pública do campo, mantendo, portanto, a continuidade de uma política de educação voltada para os povos do campo.

\section{Considerações finais}

O que se observa no Projeto de Lei $n^{\circ} 8.035$ é que algumas frentes de lutas e demandas dos movimentos sociais de trabalhadores estão apontadas como metas e estratégias. É o caso da educação infantil, a educação especial no contexto do campo e da cidade, a formação continuada dos profissionais da educação, infraestrutura para o funcionamento das escolas, reconhecimento da diversidade sociocultural, ênfase nos aspectos pedagógicos e materiais didáticos.

Constata-se que, nos últimos anos, as conquistas no plano educacional e político foram significativas. Em praticamente dez anos foram aprovadas diretrizes nacionais da educação do campo, diretrizes estaduais, decreto presidencial, participação dos povos do campo na Conferência Nacional de Educação, inserção das demandas educacionais dos povos do campo no Projeto de Lei $n^{0} 8.035$, efetivação de cursos de Educação Superior para os beneficiários da reforma agrária, etc.
Contudo há muitas outras propostas que foram discutidas na CONAE e que estão distantes das diretrizes e metas do Projeto de Lei $\mathrm{n}^{\circ} 8.035$, tais como: a transversalidade da educação do campo na educação básica e superior; a interface da educação especial na educação do campo; política pública de financiamento da educação do campo; gestão da educação da educação do campo, etc.

Entretanto, cabe indagar: O documento final do PNE 2011-2020 aprovará uma política de educação do campo referendada pelos movimentos sociais? As metas e estratégias serão cumpridas? Quais dificuldades estarão postas nos estados cujos governos recusam o diálogo com os movimentos sociais do campo? A realidade dos municípios brasileiros, no que tange à educação do campo, é semelhante: professores temporários, precariedade do transporte escolar de alunos e professores, carência de atendimento educacional especializado, e material didático frágil no que diz respeito ao tema campo brasileiro. Como articular os municípios, estados e a União no desenvolvimento da educação do campo? As maiores dificuldades residem no plano municipal? Como superá-las?

Cabe aos vários segmentos da sociedade, movimentos sociais do campo, sindicatos, pais, alunos, profissionais da educação e organismos das instituições da comunidade científica articularem-se para forçar melhorias no Projeto de Lei, acompanhando a sua tramitação no Congresso Nacional e verificando se de fato ele avança em direção às reivindicações dos movimentos sociais na defesa de uma educação pública e de qualidade. Como afirma Monlevade (2010, p. 15):

O PNE não é um plano qualquer, mas um plano de educação, que vive o conflito permanente entre o que é e o que deve ser, entre o lugar de raiz e a utopia, a nossa viagem do egoísmo para a terra dos valores coletivos. Haja clareza, haja vontade e haja dinheiro $[\ldots]$

\section{REFERÊNCIAS}

BRASIL. Lei $\mathrm{n}^{\circ}$ 8.315, de 23 de dezembro de 1991. Dispõe sobre a criação do Serviço Nacional de Aprendizagem Rural - SENAR, nos termos do artigo 62 do Ato das Disposições Constitucionais Transitórias. Diário Oficial [da] República Federativa do Brasil, Poder Legislativo, Brasília, DF, 24 dez. 1991. Disponível em:<http://www.senarpr. org.br/arrecadacao/lei_8315_1991.pdf>. Acesso em: 26 fev. 2011. 
BRASIL. Lei n ${ }^{\circ}$ 9.394, de 20 de dezembro de 1996. Estabelece as diretrizes e bases da educação nacional. Diário Oficial [da] República Federativa do Brasil, Poder Legislativo, Brasília, DF, 23 dez. 1996. p. 27833.Disponível em: $<$ http://www6.senado.gov.br/legislacao/ListaTextoIntegral.action?id=75723>. Acesso em: 26 fev. 2011.

BRASIL. Ministério da Educação. Resolução CNE/CEB n ${ }^{0}$ 1, de 3 de abril de 2002. Institui Diretrizes Operacionais para a Educação Básica das Escolas do Campo. Diário Oficial da União, Poder Legislativo, Brasília, DF, 9 abr. 2002. Disponível em:<http://portal.mec.gov.br/cne/arquivos/pdf/CEB012002.pdf>. Acesso em: 23 fev. 2011.

BRASIL. Ministério da Educação. Resolução n ${ }^{\circ}$ 2, de 28 de abril de 2008. Estabelece diretrizes complementares, normas e princípios para o desenvolvimento de políticas públicas de atendimento da Educação Básica do Campo. Diário Oficial da União, Poder Legislativo, Brasília, DF, 29 abr. 2008. Disponível em:<http://portal.mec.gov.br/ cne/arquivos/pdf/2008/rceb002_08.pdf > . Acesso em: 23 fev. 2011.

BRASIL. Decreto $n^{0} 7.352$, de 4 de novembro de 2010. Dispõe sobre a política de educação do campo e o Programa Nacional de Educação na Reforma Agrária - PRONERA. Diário Oficial da União, Poder Legislativo, Brasília, DF, 5 nov. 2010a. Disponível em: $<$ http://www.planalto.gov.br/ccivil_03/_Ato20072010/Decreto/D7352.htm>. Acesso em: 23 fev. 2011.

BRASIL. Ministério da Educação. Projeto de Lei no 8.035, de 20 de dezembro de 2010. Aprova o Plano Nacional de Educação para o decênio 2011-2020 e dá outras providências. Diário Oficial da União, Poder Legislativo, Brasília, DF, 20 dez. 2010b. Disponível em: <http://www.camara.gov.br/sileg/Prop_Detalhe.asp?id=490116>. Acesso em: 23 fev. 2011.

CALDART, Roseli Salete. A escola do campo em movimento. Currículo sem Fronteiras, v. 3, n. 1, p. 60-81, jan./ jun. 2003. Disponível em: $<$ http://www. curriculosemfronteiras.org/vol3iss1articles/roseli2.pdf $>$. Acesso em: 18 mar. 2011.

CALDART, Roseli Salete. Por uma educação do campo: traços de uma identidade em construção. In: ARROYO, Miguel Gonzalez; CALDART, Roseli Salete; MOLINA, Mônica Castagna (Org.). Por uma educação do campo. Petrópolis: Vozes, 2004. p. 147-158.

CONFERÊNCIA NACIONAL DE EDUCAÇÃO - CONAE. Construindo o Sistema Nacional Articulado de Educação: o Plano Nacional de Educação, diretrizes e estratégias de ação. Brasília, DF: MEC, 2010. Disponível em: $<$ http://portal.mec.gov.br/arquivos/pdf/conae/documento_referencia.pdf $>$. Acesso em: 10 mar. 2011.

FERNANDES, Bernardo Mançano. Primeira Conferência Nacional "Por uma Educação Básica do Campo". In: ARROYO, Miguel Gonzalez; CALDART, Roseli Salete; MOLINA, Mônica Castagna. (Org.). Por uma educação do campo. Petrópolis: Vozes, 2004. p. 19-64.

FRIGOTTO, Gaudêncio. Projeto Societário contra-hegemônico e educação do campo: desafios de conteúdo, método e forma. In: MUNARIM, Antonio et al. (Org.). Educação do campo: reflexões e perspectivas. Florianópolis: Insular, 2010. p. 19-46.

INSTITUTO BRASILEIRO DE GEOGRAFIA E ESTATÍSTICA - IBGE. Censo Demográfico 2000. Rio de Janeiro: IBGE, 2000. Disponível em:<http://www.ibge.gov.br/home/estatistica/populacao/censo2000/universo. php?tipo $=31 \mathrm{o} /$ tabela13_1.shtm\&uf=41>. Acesso em: 10 mar. 2011.

INSTITUTO BRASILEIRO DE GEOGRAFIA E ESTATÍSTICA - IBGE. Contagem da População 2007. Rio de Janeiro: IBGE, 2007. Disponível em:<http://www.ibge.gov.br/home/estatistica/populacao/contagem2007/contagem. pdf>. Acesso em: 5 mar. 2011.

INSTITUTO NACIONAL DE COLONIZAÇÃO E REFORMA AGRÁRIA - INCRA. I Censo Nacional da Reforma Agrária. Brasília, DF: MEPF, 1996.

INSTITUTO NACIONAL DE ESTUDOS E PESQUISAS EDUCACIONAIS ANÍSIO TEIXEIRA - INEP. Panorama da Educação do Campo. Brasília, DF: INEP, 2007. Disponível em: <http://www.red-ler.org/panoramaeducacao-campo.pdf>. Acesso em: 5 mar. 2011.

MARCOCCIA, Patrícia Correia de Paula. Escolas Públicas do Campo: indagação sobre a educação especial na perspectiva da inclusão educacional. 2011. 191 f. Dissertação (Mestrado em Educação) - Universidade Tuiuti do Paraná, Curitiba, 2011.

MONLEVADE, João Antônio Cabral de. Plano Nacional de Educação 2011-2020: um esboço. Brasília: Senado Federal, 2010. (Coleção Consultoria Legislativa). Disponível em: $<$ http://www.senado.gov.br/senado/conleg/Agenda_legislativa/Capitulo_20_Joao_Monlevade.pdf $>$. Acesso em: 16 mar.2011. 
MUNARIM, Antônio et al. Política pública de educação do campo: a articulação entre o Estado e a sociedade. In: AUED, Bernadete Wrublevski; VENDRAMINI, Célia Regina (Org.). Educação do campo: desafios teóricos e práticos. Florianópolis: Insular, 2009. p. 53-65.

PEREIRA, Roberval Eloy. A consolidação de escolas unidocentes como política de educação para a zona rural no estado do Paraná. São Paulo: AnnaBlume; Curitiba: Fundação Araucária, 2002.

SOUZA, Maria Antônia de. Educação e movimentos sociais do campo: a produção do conhecimento no período de 1987 a 2007. Curitiba: UFPR, 2010.

VEIGA, José Eli da. Cidades imaginárias: o Brasil é menos urbano do que se calcula. 2. ed. Campinas: Autores Associados, 2003.

VERDE, Valéria Villa. Territórios, ruralidade e desenvolvimento. Curitiba: IPARDES, 2004.

Recebido em 24.05.2011

Aprovado em 11.08.2011 